\title{
Effectiveness of Integrative Restoration (iRest) Yoga Nidra on Mindfulness, Sleep, and Pain in Health Care Workers
}

\author{
Eva Livingston \\ Katreena Collette Merrill \\ Brigham Young University - Provo, katreena.merrill@byu.edu
}

Follow this and additional works at: https://scholarsarchive.byu.edu/facpub

Part of the Other Nursing Commons

\section{Original Publication Citation}

Livingston, E. \& Merrill, K.C. (2018). Effectiveness of Integrative Restoration iRest Yoga Nidra on Mindfulness, Sleep and Pain in Health Care Workers. Holistic Nursing Practice. 32(3), 160-166.

\section{BYU ScholarsArchive Citation}

Livingston, Eva and Merrill, Katreena Collette, "Effectiveness of Integrative Restoration (iRest) Yoga Nidra on Mindfulness, Sleep, and Pain in Health Care Workers" (2018). Faculty Publications. 5254.

https://scholarsarchive.byu.edu/facpub/5254

This Peer-Reviewed Article is brought to you for free and open access by BYU ScholarsArchive. It has been accepted for inclusion in Faculty Publications by an authorized administrator of BYU ScholarsArchive. For more information, please contact ellen_amatangelo@byu.edu. 


\title{
Effectiveness of Integrative Restoration (iRest) Yoga Nidra on Mindfulness, Sleep, and Pain in Health Care Workers
}

\author{
Eva Livingston, RN, BSN $\square$ Katreena Collette-Merrill, PhD, RN
}

\begin{abstract}
This article examines the effectiveness of Integrative Restoration (iRest) Yoga Nidra meditation on mindfulness, sleep, and pain in health care workers. As health care workers provide emotional support to patients, it is not uncommon for workers to experience both physical and mental exhaustion. One holistic approach to support employees is mindfulness training. iRest Yoga Nidra is a complementary and integrative health therapy that increases mindfulness. A pre-/postinterveniton descriptive survey design was used. Before and after experiencing iRest meditation, participants completed a 51-item questionnaire consisting of demographics plus 3 validated instruments: the Five-Facet Mindfulness Questionnaire (FFMQ), the Epworth Sleepiness Scale (ESS), and Department of Defense/Veterans Administration (DoD/NA) Pain Supplemental Questions (PSQ). A total of 15 participants completed both questionnaires. Postintervention FFMQ scores were significantly higher than preintervention $(z=-3.294, P=.001)$. The highest subscale scores were "acting with awareness" and "nonjudging of inner experience." There was a not a significant difference in the mean ESS scores at baseline and follow-up. However, there was a strong negative correlation between the mean ESS improvement score and the number of weeks attended $\left(r_{\mathrm{s}}=-0.705, P=.003\right)$. There was a not a significant difference in the mean pain baseline and follow-up scores. This study showed significant improvement in mindfulness of health care workers following a guided 8-week iRest Yoga Nidra program. The results of this study may provide some insight into helping health care workers deal with the demands of their profession in a positive manner, thus leading to an improved workplace environment. KEY WORDS: meditation, mindfulness, workplace wellness, Yoga Nidra Holist Nurs Pract 2018;32(3):160-166
\end{abstract}

\section{INTRODUCTION}

Health care is a physically and emotionally demanding profession. Shift work and the 24-hour nature of health care contributes to abnormal sleep patterns, fatigue, burnout, pain, and employee injuries ${ }^{1-3}$ The most common employee concerns in health care are musculoskeletal conditions followed by emotional pressures, both of which may contribute to pain, sleep disruption, burnout, missed work, and decreased satisfaction. ${ }^{4}$

\footnotetext{
Author Affiliations: Dixie Regional Medical Center, Intermountain Healthcare, St George, Utah (Ms Livingston); and Brigham Young University, Provo, Utah (Dr Collette-Merrill).
}

The authors have disclosed that they have no significant relationships with, or financial interest in, any commercial companies pertaining to this article.

Correspondence: Katreena Collette-Merrill, $\mathrm{PhD}, \mathrm{RN}$, College of Nursing, Brigham Young University, 500 Spencer Kimball Tower, Provo, UT 84602 (katreena.merrill@byu.edu).

DOI: 10.1097/HNP.0000000000000266
As health care workers provide emotional support to patients, it is not uncommon for workers to experience both physical and mental exhaustion. In 2 studies of more than 1500 and 3000 nurses, $34.3 \%$ of nurses reported insomnia symptoms and $57 \%$ reported sleep deficiencies. ${ }^{5-6}$ Further, $73 \%$ to $90 \%$ of nurses reported back pain in the past 1 to 3 months. ${ }^{5,7-8}$

To combat the physical and emotional demands of health care, many employers offer workplace wellness programs (WWPs). Most WWPs target overall employee health, hoping to increase preventative care and lower employer associated health care costs. ${ }^{9}$ Few programs, however, focus on employee psychological wellness. ${ }^{10}$ Failure to consider employee psychological wellness is of particular concern for health care workers because the nature of their work makes them vulnerable for psychological harm, resulting in compassion fatigue and burnout. ${ }^{11}$ Workplace wellness programs therefore need to consider including holistic approaches that focus on supporting employees' physical and psychological well-being. ${ }^{12}$ 
One holistic approach to support employees is mindfulness training. When a person is taught how to experience mindfulness, they learn how to bring their complete attention to current experiences with an accepting attitude toward oneself. This helps individuals develop voluntary control over their mental well-being and thereby increase calmness, clarity, and concentration. ${ }^{13}$ For example, 2 separate randomized controlled trials studying the effects of mindfulness meditation training reported that students who participated in mindfulness meditation were able to reduce perceived stress and rumination. ${ }^{13-14}$ Furthermore, in a randomized controlled trial with persons with generalized anxiety disorder, researchers reported that mindfulness meditation improved perceived stress reactivity and coping. ${ }^{15}$ Teaching individuals mindfulness meditation strategies helps them address their physical, mental, and spiritual well-being and is therefore one holistic approach that may be effective for nurses in particular.

There are many types of mindfulness training, and one such is iRest Yoga Nidra. Yoga Nidra refers to the conscious awareness of the deep sleep state. iRest Yoga Nidra was developed over the past 26 years by Richard Miller, PhD, a clinical psychologist. ${ }^{16}$ iRest Yoga Nidra differs from traditional Yoga. iRest is a complementary and integrative health therapy that is both integrative and restorative. It is integrative as participants are taught to work to resolve issues of the body and mind and restorative because it helps participants recognize there is an underlying peace of mind despite the chaos found in their lives. In contrast to traditional yoga, iRest involves no movement and the participant experiences iRest in a supine or reclined position with their eyes closed. The goal of iRest is for the participant to acknowledge and invite natural feelings, memories, or emotions (Figure). ${ }^{16}$ iRest has been used as a successful intervention with military veterans, persons with physical and mental disabilities, college students, and health care workers.

Researchers studying the effect of iRest Yoga Nidra in the military population report favorable results. ${ }^{17} \mathrm{In}$ a 2014 study of 13 women veterans, $86 \%$ with sexual trauma who participated in twice weekly iRest Yoga Nidra sessions for 10 weeks reported that they were better able to handle stress and make changes in their life. ${ }^{17}$ In another study of 16 posttraumatic stress disorder male veterans, 11 participants $(68 \%)$ who completed 8 weekly iRest classes reported reduced rage, reduced anxiety, and reduced emotional reactivity. ${ }^{18}$ In addition to reducing negative stressors, participants experienced increased feelings of relaxation, peace, self-awareness, and self-efficacy, despite their challenges with mental focus, intrusive memories, and other concerns. ${ }^{18}$

iRest Yoga Nidra has also been studied in populations with mental and physical disabilities. In a 2012 study with 148 subjects being treated for chemical dependence in a residential treatment facility, subjects were randomly assigned to a ten 1-hour sessions of iRest meditation treatment versus treatment as usual. Authors reported that 52 subjects (73\%) who completed the 10 -week iRest meditation sessions experienced decreased relapse rates by creating a mindfulness state and decreasing negative mood states. ${ }^{19}$ In addition, in a study including a convenience sample of 22 patients ( 10 with cancer and 12 with multiple sclerosis), a significant reduction in stress was reported following 6 weekly 90-minute iRest sessions. ${ }^{20}$

The effect of iRest Yoga Nidra has also been studied in healthy populations. In a study with a convenience sample of 174 college students aged 18 to 56 years, the 66 participants $(37 \%)$ who attended weekly 2-hour iRest Yoga Nidra sessions for 8 weeks reported a significant reduction in stress, worry, and depression. ${ }^{21}$ In another study of a convenience sample of 26 school counselors, 22 (84\%) who completed an iRest Yoga Nidra program self-reported decreased stress and fatigue. ${ }^{22}$

iRest also has the potential to impact health care workers. In the health care population, a study of 19 health care workers from a military medical center reported an improvement in sleep scores following a 6 -week iRest Yoga Nidra program. The completion rate for the program was $74 \%$. The authors concluded that iRest was a feasible program to reduce daytime sleepiness; however, they recommended further study. ${ }^{16}$

The aim of this pilot study was to examine the effectiveness of Integrative Restoration (iRest) Yoga Nidra meditation on mindfulness, sleep, and pain in health care workers.

\section{METHODS}

A pre-/postintervention descriptive survey design was used to measure the effect and of eight 1-hour weekly iRest Yoga Nidra sessions on the mindfulness, sleep, and pain in health care workers. Following institutional review board approval, a convenience sample was recruited via fliers and network sampling. 


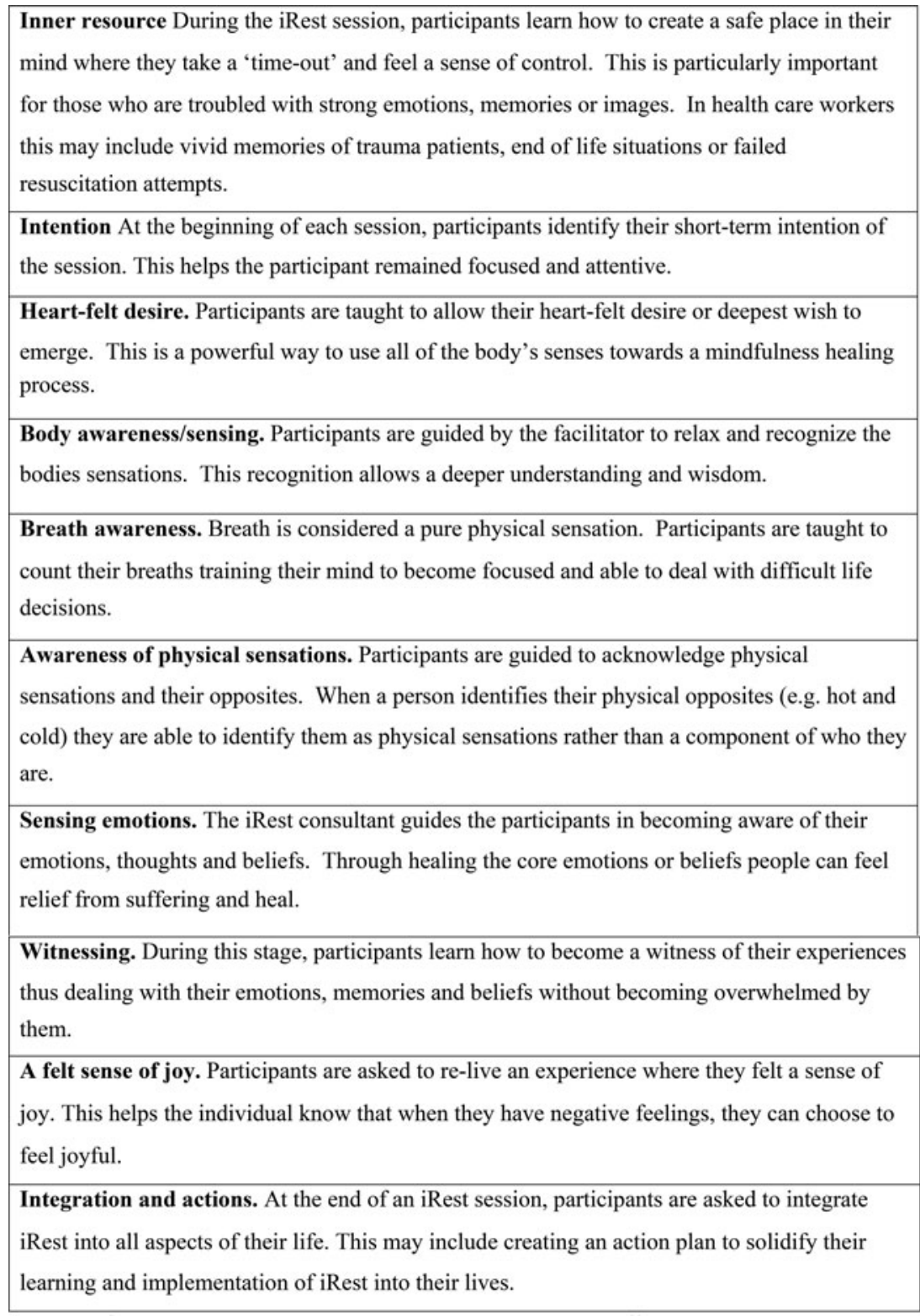

(Adapted from Integrative Restoration Institute, 2012; Pence, Katz, Huffman, \& Cojucar, 2014).

FIGURE. Components of the iRest Yoga Nidra process.

Participants were eligible if they were between the ages 18 and 65 years, were employees of the organization, and self-reported that they were not being treated by a health care provider for any long-term illness.

After completing a written informed consent, participants completed a 51-item baseline questionnaire consisting of demographics (age, gender, ethnicity, and education level) plus 3 validated instruments measuring mindfulness, sleep, and pain. A certified iRest consultant then guided participants in eight 1-hour individual weekly iRest sessions. During the iRest meditation experiences, participants were taught the systematic and direct 10-stage process of iRest. Components of the iRest process are briefly described in the Figure. Each iRest session built on the experiences from the previous session. Participants were also offered an optional opportunity to listen to the meditation on their own at home via compact disc (CD) recording of the guided meditation. The $\mathrm{CD}$ was intended to be supplemental rather than a replacement for in-person sessions. At the end of the last iRest session, participants completed the same survey and self-reported their completion of home meditation.

Three validated instruments plus demographics were used to measure mindfulness, sleep, and pain of 
the health care workers before and after an 8-week iRest Yoga Nidra program. Mindfulness was measured using the Five-Facet Mindfulness Questionnaire (FFMQ), a 39-item questionnaire. The FFMQ is based on 5 independently developed mindfulness questionnaires. ${ }^{23}$ The 5 facets measured include observing, describing, acting with awareness, nonjudging of inner experience, and nonreactivity to inner experience. Participants self-reported their mindfulness using a 1 - to 5-point Likert scale $(1=$ never or very rarely true; $5=$ very often or always true). Validity and reliability of the instrument is reported elsewhere. ${ }^{23}$

Sleepiness was measured using the Epworth Sleepiness Scale (ESS). The ESS has been used to measure average daytime sleepiness in several studies. ${ }^{1,24}$ The ESS differentiates between average sleepiness and excessive daytime sleepiness, which requires intervention. Participants self-rated how likely they were to doze, given 8 different situations. Scoring of the answers was 0 to 3 , with 0 being "would never doze" and 3 being "high chance of dozing" in each example situation. Summed scores are then categorized (scores $<10=$ unlikely you are abnormally sleepy; scores $\geq 10=$ excessively sleepy should seek medical attention). Possible scores ranged from 0 to $24 .^{24}$

Pain was measured by the Department of Defense/Veterans Administration (DoD/VA) Pain Supplemental Questions (PSQ) for clinicians to evaluate the biophysical impact of pain. ${ }^{25}$ The DoD/VA PSQ is a 4-item questionnaire asking participants to score on a 0 - to 10 -point scale how pain affects their usual activities. Scores are summed and divided by the number of items in the survey (4) to obtain an average pain score. Lower scores indicate less pain. Validity and reliability of this instrument is reported elsewhere. ${ }^{25}$ The 3 instruments used in this study were chosen based upon their previously reported validity and reliability and their use in previous research studies about the effectiveness of iRest. ${ }^{13,17-18,20-23,25}$

Data from hard copy questionnaires were entered into SPSS version $23 .{ }^{26}$ Descriptive statistics were completed for both the baseline and follow-up data. Mean scores of each of the FFMQ, ESS, and pain variables were calculated before and after the intervention. Because the data were skewed, a Wilcoxon signed rank test was run to determine whether there was a significant improvement in mindfulness, sleep, and pain. A Spearman rank correlation statistic was conducted to determine whether there was a relationship between the number of iRest meditation sessions and improvement scores for the outcome measures.

For categorical variables, the ESS score was calculated and categorized into 2 categories (not sleepy score $=<10$; excessively sleepy score $=\geq 10$ ). Categorical variables were also calculated for attending iRest sessions $(0=<4$ sessions; $1=5$ or more sessions $)$ and practicing meditation at home $(0=$ no practice at home; $1=$ practice at home). A 2-sided Fisher exact statistic was calculated to determine whether there was a significant association between subjects responding in the excessively sleepy category after the intervention and in subjects who attended 5 or more iRest sessions and who practiced meditation at home. Because this was a pilot study, no power analysis was conducted a priori to determine the needed sample size.

\section{RESULTS}

A total of 22 healthy employee volunteers were recruited to participate. The final sample included 15 participants who completed both the baseline and follow-up questionnaires (completion rate $=68 \%$ ). Information was not collected about why participants did not complete the program. Participants were Caucasian (93\%) and women (80\%). A total of $60 \%$ $(n=9)$ reported some college education and the average age was 44 years (standard deviation [SD] = 14). Participants attended between 4 and 8 of the weekly iRest sessions (mean $=6$; $\mathrm{SD}=1.4$ ). Fewer than half of the participants practiced meditation at home $(47 \%)$.

The baseline FFMQ scores ranged from 2.7 to 3.4 (5-point scale), with an overall baseline mean FFMQ of $2.9(\mathrm{SD}=0.6)$. The lowest baseline score was in the facet of "acting with awareness" (mean $=2.7$; $\mathrm{SD}=0.8)$, and the highest score was in the facet of "observing" (mean $=3.4 ; \mathrm{SD}=0.8$ ). The follow-up FFMQ scores ranged from 3.5 to 3.9 , with a mean overall follow-up FFMQ of $3.6(\mathrm{SD}=0.4)$. The highest increase in scores from baseline compared with follow-up was in the facets "acting with awareness" and "nonjudging of inner experience." The postintervention FFMQ scores were significantly higher than the preintervention FFMQ scores $(z=$ $-3.294, P=.001)$. A significant improvement in mindfulness scores was also reported in each of the 
TABLE 1. Five-Facet Mindfulness Questionnaire Baseline and Follow-up Scores

\begin{tabular}{|c|c|c|c|c|}
\hline Item & Definition & $\begin{array}{l}\text { Baseline } \\
\text { Mean (SD) }\end{array}$ & $\begin{array}{l}\text { Follow-up } \\
\text { Mean (SD) }\end{array}$ & $\begin{array}{l}\text { Wilcoxon Signed } \\
\text { Rank Test } Z \text { Score } \\
\text { Results ( } P \text { Value) }\end{array}$ \\
\hline Observing & Attending to events and emotions & $3.4(0.76)$ & $3.9(0.55)$ & $-2.872(.001)$ \\
\hline Describing & $\begin{array}{l}\text { Labeling experiences such as } \\
\text { sensations/cognitions }\end{array}$ & $3.0(1.0)$ & $3.6(0.75)$ & $-3.066(.002)$ \\
\hline Acting with Awareness & Focusing attention on current activities & $2.7(0.82)$ & $3.5(0.63)$ & $-3.081(.002)$ \\
\hline $\begin{array}{l}\text { Nonjudging of inner } \\
\text { experience }\end{array}$ & $\begin{array}{l}\text { Refraining from evaluation of thoughts/ } \\
\text { feelings }\end{array}$ & $2.9(0.85)$ & $3.8(0.82)$ & $-3.111(.002)$ \\
\hline $\begin{array}{l}\text { Nonreactivity to inner } \\
\text { experience }\end{array}$ & $\begin{array}{l}\text { Noticing thoughts and feelings without } \\
\text { showing a reaction toward them }\end{array}$ & $2.9(0.84)$ & $3.5(0.55)$ & $-2.698(.007)$ \\
\hline Total FFMQ & & $2.9(0.65)$ & $3.6(0.47)$ & $-3.294(.001)$ \\
\hline
\end{tabular}

Abbreviations: FFMQ, Five-Facet Mindfulness Questionnaire; SD, standard deviation.

FFMQ subscales (Table 1). There was no correlation between the number of sessions an individual attended and mindfulness improvement scores $\left(r_{\mathrm{s}}=-0.390\right.$, $P>.05)$. Cronbach $\alpha$ reliability for the entire FFMQ scale was 0.937 , with the subscales ranging from a Cronbach $\alpha$ of 0.794 to 0.921 .

The mean ESS score at baseline was 8.5, with $66 \%$ of the participants scoring "unlikely to be abnormally sleepy" or average daytime sleepiness and a third (33\%) scored as excessively sleepy depending on the situation. Following the intervention, the mean ESS score was 6.9 , with $87 \%$ scored "unlikely to be abnormally sleepy" or average daytime sleepiness, with $13 \%$ excessively sleepy depending on the situation. There was a not a significant difference in the mean ESS scores at baseline (mean $=8.4, \mathrm{SD}=$ 3.9) and mean follow-up ESS scores (mean $=6.9$,
$\mathrm{SD}=2.3 ; z=-1.731 ; P=.083)$. However, there was a strong negative correlation between the mean ESS improvement score and the number of weeks attended $\left(r_{\mathrm{s}}=-0.705, P=.003\right)$. For example, the more sessions attended, the less sleepiness was reported. Categorical analysis revealed that there was also no significant change in sleepy versus nonsleepy categories following the intervention, nor was there an association between sleepiness category and number of iRest sessions attended or practicing meditation at home $(P=.571)$ (Table 2). The Cronbach $\alpha$ measuring scale reliability was 0.343 , indicating that the ESS was not very reliable in this study population.

At baseline, participants reported mean overall pain scores ranging from 0 to 8.2 on a 10 -point scale (mean $=2.6, \mathrm{SD}=2.6$ ). Following the intervention, mean overall pain ratings ranged from 0 to 7.7 (mean $=2.0$,

TABLE 2. Epworth Sleep Scale: What Is Your Chance of Dozing?a

\begin{tabular}{|c|c|c|c|}
\hline Score & Definition & Baseline, n (\%) & Follow-up, n (\%) \\
\hline $0-7$ & $\begin{array}{l}\text { Unlikely that you are abnormally } \\
\text { sleepy }\end{array}$ & $5(33)$ & $10(67)^{b}$ \\
\hline $8-9$ & $\begin{array}{l}\text { Average amount of daytime } \\
\text { sleepiness }\end{array}$ & 5 (33) & $3(20)^{b}$ \\
\hline $10-15$ & $\begin{array}{l}\text { Excessively sleepy depending on } \\
\text { situation }\end{array}$ & $5(33)$ & $2(13)^{b}$ \\
\hline \multirow[t]{2}{*}{$16-24$} & $\begin{array}{l}\text { Excessively sleepy seek medical } \\
\text { attention }\end{array}$ & 0 & $0^{\mathrm{b}}$ \\
\hline & & $\begin{array}{l}\text { Baseline } \\
\text { Mean (SD) }\end{array}$ & $\begin{array}{l}\text { Follow-up } \\
\text { Mean (SD) }\end{array}$ \\
\hline Total Score & Overall ESS score & $8.5(3.9)$ & $6.9(2.3)^{c}$ \\
\hline
\end{tabular}


$\mathrm{SD}=2.3)($ Table 3). There was not a significant difference in the mean DoD/VA Pain Questionnaire baseline and follow-up scores $(z=-1.380 ; P=.168)$. There was also no significant relationship between attending meditation sessions and improvement in pain scores $\left(r_{\mathrm{s}}=-0.178, P>.05\right)$. The Cronbach $\alpha$ reliability of the pain scale was 0.9340

\section{DISCUSSION}

The health care profession can be demanding. While health care workers are trained in compassion and empathy, they have not been taught how to cope with the negative aspects of providing health care. A lack of coping strategies is concerning because unresolved work-related issues can lead to compassion fatigue and burnout, which are patient safety concerns.

This study showed significant improvement in self-reported mindfulness scores of health care workers following a guided 8-week iRest Yoga Nidra program. For example, participants reported that they were better able to focus their attention on current activities (acting with awareness) and become aware of the tendency to be ruled by an internal critic (nonjudging). The results of this study may provide some insight into helping health care workers deal with the physical and emotional demands of their profession in a positive manner, thus leading to an improved workplace environment.

This study did not find a significant change in employee sleepiness or pain following the iRest meditation intervention. The nonsignificant findings were most likely due to the low baseline scores for both measures, indicating the participants were well rested and not in pain at baseline. This is interesting

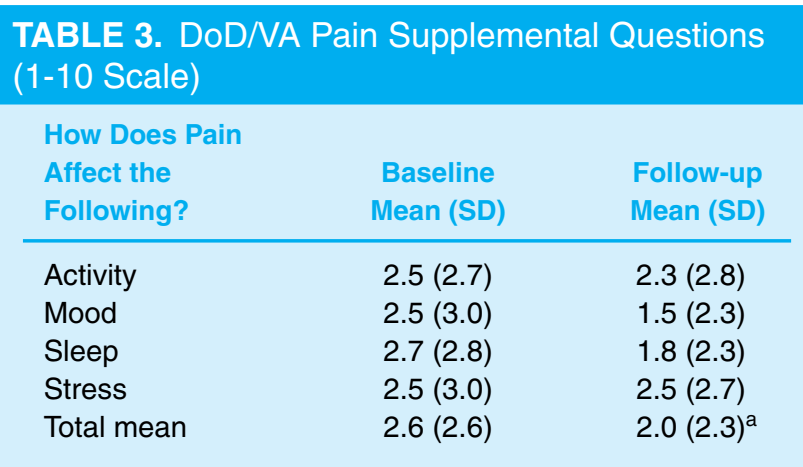

Abbreviations: DoD/VA, Department of Defense/Veterans Administration; SD, standard deviation.

${ }^{\mathrm{a}} Z=-1.380 ; P=.168$. because researchers report that musculoskeletal disorders are the most common work-related injury in health care. ${ }^{4}$

It is important to note that the iRest sessions were offered during the evening hours when most night-shift workers are scheduled. Therefore, the study most likely self-selected daytime workers. Only 15 of the 22 participants (68\%) completed the 8-week study. While attrition is always a concern, this attrition rate is similar to other iRest studies. ${ }^{18-19}$ Furthermore, a limitation of the study is the type of shift worked and role at the hospital was not collected in the demographic information. Additional research is needed on the effect of iRest in night-shift employees. This was a descriptive study with a small sample using a convenience sample. The investigators did not use a control group and the pre- and postsurvey design may have resulted in test/retest bias. In addition, the intervention occurred over a short period. Furthermore, mindfulness, sleep, and pain were the only measures studied. Other measures such as quality of life, stress, or work satisfaction may have been helpful measures to include in future research. Despite the limitations of this study, the results may be used to inform future research on holistic employee wellness programs.

The findings from this study can be used to inform WWPs. In a recent Forbes magazine report, they challenged employers to reach beyond typical wellness programs such as gym memberships and provide holistic wellness programs. ${ }^{27}$ Employers within and outside of health care are looking for holistic approaches to their WWP. ${ }^{9,12,28}$ Findings from this study are important because they add to the body of knowledge about mindfulness meditation and reaffirm its usefulness in healthy adults, particularly in health care workers.

The findings from this study contribute to the knowledge of holistic nursing practice. Holistic practices bring together the physical, mental, and spiritual aspects of health and well-being. ${ }^{12}$ Nurses can become more familiar with integrated approaches such as iRest and use these to increase mindfulness in their patients, coworkers, and themselves. Nurses also have an influence on work and wellness programs. Employee wellness programs are consistently on the rise. Including mindfulness interventions such as iRest Yoga Nidra into WWPs may lead to the discovery that these interventions empower employees to improve their health behaviors. ${ }^{29}$

For iRest to be successful, a certified iRest consultant is needed who can lead the sessions. Many 
iRest consultants prefer to have 2 consultants per session in the event one of the participants needs additional support. iRest Certification is a professional designation. Level I, Basic iRest training is a 4- to 5-day training that costs about $\$ 1500$ to $\$ 2000$. Participants receive up to 30 continuing education hours and provide the basic principles, history, theory, practice, and delivery of iRest. Level II training is advanced and is similar in time, cost, and continuing education. To become a certified iRest Teacher, the participant must attend at least 2 authorized iRest retreats, a written examination, supervision and support by an iRest Supervisor. There is an additional cost for iRest certification. ${ }^{16}$

In addition, for iRest and other holistic measures to be effective in the workplace, employers should provide a physical environment conducive to iRest sessions (space considerations, quiet environment undisturbed). Furthermore, workplace culture itself must be open and embrace holistic approaches to accommodate iRest Nidra meditation. ${ }^{10}$

\section{REFERENCES}

1. Jafari-Roodbandi A, Choobineh A, Daneshvar S. Relationship circadian rhythm amplitude and stability with sleep quality and sleepiness among shift nurses and health care workers. Int J Occup Saf Ergon. 2015;21(3):312-317. doi:10.1080/10803548.2015.1081770.

2. Occupational Health and Safety Administration. Worker safety in our hospitals: care for our caregivers. https://www.osha.gov/dsg/hospitals/. Published 2016. Accessed May 1, 2017.

3. Smith-Miller CA, Shaw-Kokot J, Curro B, Jones CB. An integrative review: fatigue among nurses in acute care settings. J Nurs Adm. 2014;44(9):487-494. doi:10.1097/NNA.0000000000000104.

4. Guillaumie L, Boiral O, Champagne J. A mixed-methods systematic review of the effects of mindfulness on nurses. $J$ Adv Nurs. 2017;73(5):1017-1034

5. Buxton OM, Hopcia K, Sembajwe G, et al. Relationship of sleep deficiency to perceived pain and functional limitations in hospital patient care workers. J Occup Environ Med. 2012;54(7):851-858. doi:10.1097/JOM.0b013e31824e6913.

6. Portela LF, Kröning Luna C, Rotenberg L, et al. Job strain and self-reported insomnia symptoms among nurses: what about the influence of emotional demands and social support? Biomed Res Int. 2015;2015:820610. doi:10.1155/2015/820610.

7. Adhikari S, Dhakal G. Prevalent causes of low back pain and its impact among nurses working in Sahid Gangalal National Heart Centre. J Nepal Health Res Counc. 2014;12(28):167-171.

8. June KJ, Cho SH. Low back pain and work-related factors among nurses in intensive care units. J Clin Nurs. 2011;20(3-4):479-487. doi:10.1111/j.1365-2702.2010.03210.x.

9. Mukhopadhyay S, Wendel J. Evaluating an employee wellness program. Int J Health Care Finance Econ. 2013;13(3/4):173-199. doi:1007/ s10754-013-9127-4.

10. Emerson ND, Merrill DA, Shedd K, Bilder RM, Siddarth P. Effects of an employee exercise programme on mental health. Occup Med (Lon). 2016;67(2):128-134. doi:10.1093/occmed/ kgw120.

11. Cocker F, Joss N. Compassion fatigue among healthcare, emergency and community service workers: a systematic review. Int J Environ Res Public Health. 2016;13(6). doi:10.3390/ijerph13060618.

12. Sivris KC, Leka S. Examples of holistic good practices in promoting and protecting mental health in the workplace: current and future challenges. Saf Health Work. 2015;6(4):295-304. http://dx.doi.org/10.1016/j.shaw. 2015.07.002.

13. Jain S, Shapiro SL, Swanick S, et al. A randomized controlled trial of mindfulness meditation versus relaxation training: effects on distress, positive states of mind, rumination, and distraction. Ann Behav Med. 2007;33:11-21.

14. Shapiro SL, Oman D, Thoresen CE, Plante TG, Flinders T. Cultivating mindfulness: effects on well-being. J Clin Psychol. 2008;64:840-862.

15. Hoge EA, Bui E, Marques L, et al. Randomized controlled trial of mindfulness meditation for generalized anxiety disorder: effects on anxiety and stress reactivity. J Clin Psychiatry. 2014;74(8):786-792.

16. Integrative Restoration Institute. An introduction to Integrative Restoration-iRest ${ }^{\circledR}$ Yoga Nidra. http://www.irest.us/sites/default/ files/iRest\%20Class\%20Workbook\%207-12.pdf. Published 2012. Accessed May 1, 2017.

17. Pence PG, Katz LS, Huffman C, Cojucar G. Delivering integrative restoration Yoga Nidra Meditation (iRest ${ }^{\circledR}$ ) to women with sexual trauma at veteran's medical center: a pilot study. Int $J$ Yoga Therap. 2014;24:53-57.

18. Stanovic L. Transforming trauma: a qualitative feasibility study of integrative restoration (iRest ${ }^{\circledR}$ ) Yoga Nidra on combat-related posttraumatic stress disorder. Int J Yoga Therap. 2011;21:23-37.

19. Temme LJ, Fenster J, Ream GL. Evaluation of meditation in the treatment of chemical dependency. $J$ Soc Work Pract Addict. 2012;12(3): 264-281. doi:10.1080/1533256X.2012.702632.

20. Pritchard M, Elison-Bowers P, Birdsall B. Impact of integrative restoration (iRest ${ }^{\circledR}$ ) meditation on perceived stress levels in multiple sclerosis and cancer outpatients. Stress Health. 2010;26:233-237. doi:10.1002/smi.1290.

21. Eastman-Mueller H, Wilson T, Jung A, Kimura A, Tarrant J. iRest ${ }^{\circledR}$ Yoga-Nidra on the college campus: changes in stress, depression, worry, and mindfulness. Int J Yoga. 2013;23(2):15-24.

22. Birdsall B, Pritchard M, Elison-Bowers P, Spann J. Does integrative restoration (iRest ${ }^{\circledR}$ ) meditation decrease perceived stress levels and negative moods in school counselors. https://www.counseling.org/ docs/default-source/vistas/vistas_2011_article_84.pdf?sfvrsn=11. Published 2011. Accessed April 28, 2017.

23. Baer RA, Smith GT, Hopkins J, Krietemeyer J, Toney L. Using selfreport assessment methods to explore facets of mindfulness. Assessment. 2006;13(1):27-45.

24. Johns MW. Reliability and factor analysis of the Epworth sleepiness scale. Sleep. 1992;15(4):376-381.

25. Cleeland CS, Ryan KM. Pain assessment: global use of the brief pain inventory. Ann Acad Med Singapore. 1994;23(2):129-138.

26. IBM Corp. IBM SPSS Statistics for Windows, Version 23.0. Armonk, NY: IBM Corp; 2015

27. Forbes Coaches Council. Eight unique benefits companies should consider offering in order to attract and retain top talent. http://www. forbes.com/sites/forbescoachescouncil/2016/10/05/eight-uniquebenefits-companies-should-consider-offering-in-order-to-attract-andretain-top-talent/\#100f11a66a8c. Published 2016. Accessed April 28, 2017.

28. Person AL, Colby SE, Bulova JA, Eubanks JW. Barriers to participation in a worksite wellness program. Nutr Res Pract. 2010;4(2):149-154. http://doi.org/10.4162/nrp.2010.4.2.149.

29. McElligott D, Capitulo KL, Morris DL, Click ER. The effect of a holistic program on health-promoting behaviors in hospital registered nurses. J Holist Nurs. 2010; 28(3):175-183. 